\title{
Proposal raises bones of contention
}

Alarm is growing among anthropologists in the United States over a plan that could empty institutions of about 120,000 human skeletons currently stored for research purposes.

Under a new proposal, the bones at museums, universities and federal facilities across the nation could be given to Native American tribes now living in the area from which the remains were excavated, even if the skeletons are not culturally identifiable to the tribes. In October, the Native American Graves Protection and Repatriation Act (NAGPRA) programme, the agency that oversees the handling of American Indian remains, opened a 90-day comment period on the proposal.

It would affect ancient skeletons similar to the Kennewick Man specimen from Washington state. Scientists won a long court battle to keep that 9,000-year-old skeleton for study after attempts to give it to tribes for likely disposal.

Under current guidelines, bones that can be matched with a living tribe by using cultural evidence may be returned to them, but what to do with remains that are so old that they can't be associated with today's surviving tribes has been hotly debated for a decade.

Setting up a system to dispose of these 'culturally unidentifiable' specimens is a natural progression from NAGPRA, which became federal law in 1990 after extensive negotiations between scientists and tribes, says Sherry Hutt who manages the NAGPRA programme. "This is a proposal for disposition [in situations] such as when a new highway runs through an old graveyard," says Hutt, an attorney and economist from Arizona.

But major scientific organizations strongly dispute this view, calling the move "illegal" because it goes beyond the Congressional law, and a "divisive" manoeuvre that may shatter decades of working relationships between scientists and tribes. "The rules would be disastrous," says Phillip Walker, an anthroplogist at the University of California, Santa Barbara. A former member of NAGPRA's seven-person review committee, Walker helped prepare the American Association of Physical Anthropologists (AAPA) comments.

The AAPA says that the proposal would allow the return of almost any skeleton, even those used in medical schools, would greatly

"The proposal would hinder anatomical teaching, tive material for studies. Many almost any skeleton, of the specimens are among the even those used in oldest, offering data on the continent's first humans.

The comment period closes on 14 January, when the NAG-

PRA review committee will comment on the draft regulations. Then US Secretary of the Interior Dirk Kempthorne will issue a final decision.

Rex Dalton 